\title{
Teachers' capacity to create inclusive learning environments
}

\author{
Emma Leifler \\ Department of Women's and Children's Health,
Institutet Center of Neurodevelopmental Disorders (KIND),
Karolinska Institutet, Stockholm, Sweden and \\ Department of Women's and Children's Health,
Karolinska Institutet Center of Neurodevelopmental Disorders (KIND),
Karolinska Institutet, Stockholm, Sweden and \\ Department of Women's and Children's Health,
Institutet Center of Neurodevelopmental Disorders (KIND),
Karolinska Institutet, Stockholm, Sweden and \\ Department of Pedagogical, Curricular and Professional Studies, \\ University of Gothenburg, Gothenburg, Sweden
}

Received 5 February 2020 Revised 3 April 2020 20 April 2020

Accepted 21 April 2020

\begin{abstract}
Purpose - The purpose of this paper is to explore effects of an intervention designed for teachers' learning. This study investigates the effectiveness of a three-session professional development (PD) program based on the lesson study methodology. Lesson study was chosen as an intervention, attempting to strengthen teachers' awareness of and readiness to teach for student diversity.

Design/methodology/approach - This study included 26 participants. The teachers took part in lesson study cycles during a period of four months. Effectiveness was measured using a pre-test/post-test withinsubject design. The broad concept of inclusion and the characteristics of the research questions in this study demanded a mix of methods, a design in which qualitative and quantitative data are collected in parallel, analyzed separately and then merged.

Findings - Results show an increase of teachers' readiness from baseline to post measurement to adjust the learning environment for increased inclusivity. The largest increase ( $88 \%$ ) was seen in the themes in teachers' responses regarding accommodations for a student with special needs. Regarding self-perceived ability, the average increase was $50 \%$. Results show significant changes in teachers' adjustment awareness ability.

Originality/value - This study contributes to educational research, as the focus is PD for general teachers. PD opportunities with teaching strategies related to special needs (e.g. neurodevelopmental conditions, NDCs) are seldom offered to general education teachers. Support from teachers is a key strategy for accommodating students with special needs in mainstream classrooms. Furthermore, there is a lack of literature of interventions aiming to improve teachers' readiness and preparedness for students with NDCs in mainstream settings.
\end{abstract}

Keywords Inclusive education, Lesson study, Neurodevelopmental conditions, Self-efficacy and teachers' learning

Paper type Research paper

\section{Introduction}

Educational research has made considerable effort in trying to find the best practices and alignment between teaching actions and what students learn. Despite rigorous research in different directions with multifaceted perspectives, the question remains - what works for whom and why? Biesta (2007) evaluates the implementation of evidence-based practice in the field of education, and his critical analysis explains why "what works" does not work. He argues that there is a need to add democracy to avoid a purely technical role of educational

(c) Emma Leifler. Published by Emerald Publishing Limited. This article is published under the Creative Commons Attribution (CC BY 4.0) licence. Anyone may reproduce, distribute, translate and create derivative works of this article (for both commercial \& non-commercial purposes), subject to full attribution to the original publication and authors. The full terms of this licence may be seen at http:// creativecommons.org/licences/by/4.0/legalcode.

This study is part of the Swedish National Research School Special Education for Teacher Educators (SET), funded by the Swedish Research Council (grant no. 2017-06039), for which we are grateful. The author would also like to thank teachers and principals who participated in the study, as well as Professor Jan-Eric Gustafsson, Professor Sven Bölte and Jens Nerhall for statistical advice.

The study was supported by the Swedish Research Council. The funding organization had no role in the design and conduct of the study.

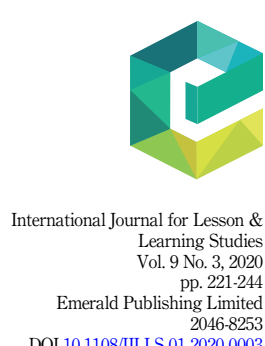

DOI 10.1108/IJLLS-01-2020-0003 
IJLLS 9,3

research and widen our thinking about the relation between research, policy and practice (p. 21). This is in line with Pring's (2000) argument that educational research is not clear enough and does not provide professionals with clear guidance, as well as Hargreaves (1997), who concluded that educational research needs to generate a cumulative body of relevant knowledge and be transformative between research and practice. All school children need support to varying degrees. Support from teachers is a key strategy for accommodating students with special needs in mainstream classrooms. The teacher is a substantially important factor for student learning (Hattie, 2013; Timperley et al., 2007; Tamm et al., 2019). Teachers are supposed to recognize the ways in which individuals learn, eliminate obstacles and create flexible learning environments (Jensen, 2017; Spencer, 2011). Collaborative development, where teachers in a systematic way analyze processes in school and classroom practice, is valuable (Lewis, 2015). The No Child Left Behind act in the US highlights areas of importance in schools (e.g. teacher qualifications), other mandates and declarations are supposed to close the gaps between student performance (e.g. the US Individuals with Disabilities Education Act, the UK Special Educational Needs and Disability Act, and the UN Salamanca Declaration). This is in line with the global goals for 2030, where inclusive education is one of the target areas for sustainability (UN, 2015). Teachers express lack of abilities for and knowledge of children with special needs, such as neurodevelopmental conditions (NDCs) (Barnhill et al., 2011; Bartonek et al., 2018), literacy difficulties (Al Otaiba and Fuchs, 2006) and dyscalculia (Sousa et al., 2017). Previous research shows a gap between goals and ideals and how inclusion can be realized in teaching (Artiles et al., 2006; European Agency, 2014; Haug, 2017). Therefore, it is important to provide teachers with opportunities for professional development (PD), such as an act for "no teacher left behind" (Jones et al., 2013, Wong et al., 2015). Additionally, teacher efficacy is associated with positive attitudes toward PD and teaching students with special educational needs (SENs) (Donohoo and Katz, 2017; Donohoo, 2018). Bandura (1977) proposed that belief in abilities was a powerful drive for one's motivation to act. Consequently, a teacher who believes in self-capability and competence therefore becomes more active and prepared for challenges. This background was the starting point for this particular study, where a short PD program was designed, conducted and evaluated. There is a need for empirical research, such as school improvement science (Lewis, 2015), where educational processes are examined and linked to the possibility for all students to participate (Haug, 2010). There is an urgent need of professional development to provide high-quality educational services for students on the autism spectrum (Odom et al., 2013). As a part of investigations designed to examine a PD program, this paper presents findings from a study conducted as an intervention.

This study focuses on the effect of a short PD program, and it is positioned between the two prevailing inclusion discourses: how to implement inclusion in practice and the individual's right to inclusion (Artiles and Waitroller, 2013). The program is cost-effective and time-efficient. Elementary and middle school teachers are greatly in need of PD that is collaborative and feasible. An identified area with existing lack of knowledge, as discussed above, is how to meet the needs of children with NDC. This PD program addresses children with SENs, specifically children with NDCs. NDC is an umbrella term covering specific neurological conditions, including autism, Asperger's syndrome, attention deficit hyperactivity disorder $(\mathrm{ADHD})$ and pervasive development disorders. Challenges in social communication and social interaction are the main characteristics of autism spectrum conditions (ASCs), which are also characteristics of ADHD. Neurodevelopmental changes in ASC impact cognitive abilities (e.g. executive functioning), processing and social cognition (Bölte et al., 2018). Executive functioning impairments among individuals with ASC are associated with increased $\mathrm{ADHD}$ symptoms (Lukito et al., 2017). All these cognitive abilities are important for successful academic achievement and self-worth and friendship quality can be low (Bottema-Beuel et al., 2019; Humphrey and Lewis, 2008; Humphrey and Symes, 2010). 
Neurodiversity requires deep knowledge and awareness that "one model" does not fit all students (Baron-Cohen, 2017). The intervention study presented in this paper aimed to see if a selection of teachers participating in a PD program with three phases, inspired by lesson study cycles, increased teachers' knowledge, preparedness and readiness to create inclusive education for children with SENs, that is, explicit NDCs. It also aimed to examine teachers' perceptions of self-efficacy. The assumption is that the program (Neurodevelopmental Conditions Awareness Intervention, or NDC AI) has an impact on teachers' knowledge and self-efficacy. More specifically, the prediction is that teachers will be more knowledgeable about how to best support children with NDC and to provide them with individual accommodations for better achievement and well-being.

\section{Research questions}

RQ1. To what extent does a short PD program enhance general teachers' readiness to create inclusive learning environment for students with NDC?

$R Q 2$. What changes in differences of perceived self-efficacy can be found after the intervention?

\section{Theoretical stances}

This study is driven by a problem of interest, not a theory; however, the study is grounded in some underlying theoretical assumptions.

\section{Philosophical worldview}

Philosophical orientation about the world, beliefs and the study of the nature of knowledge are overall positions when conducting educational research. Theoretical framework in this study is pragmatism (James and Thayer, 1975), where problems and questions (inquiry) are starting points for learning (Dewey, 1963). A rationale in the pragmatic view, is that knowledge is generated through a transaction between agent and environment. In the pragmatic paradigm, the research question is central and guides which approach is most suitable (Creswell, 2014).

\section{Professional development for teachers in general}

Professional development programs come in many forms and shapes; they vary from one momentary occasion (e.g. experts conducting workshops or seminars/lectures) to PD programs where teachers attend over a long period of time (Timperley et al., 2007). Traditionally, the "one-hit wonders" are more often discredited and PD programs have a greater deal of success (Higginson and Chatfield, 2012). Some PD initiatives are top-down and embodied with a passive view of the teacher, where the teacher needs to be exposed to new strategies and skills (Fullan and Hargreaves, 1996). PD is more effectively positioned as close to practice as possible (Hattie, 2013). Questions and outcomes should be grounded in teachers' workplaces, close to practice (Dudley et al., 2019), where teachers' collaborative work is a key trajectory for development (Holmqvist, 2017). One model for PD is lesson study, derived from Japan, and it includes a cyclic process where data is collected, analyzed and refined until educational practice is improved. The improvement is aligned with a particular topic (Marton and Tsui, 2004; Lewis et al., 2006; Lewis, et al., 2012). In a recent systematic review, Godfrey et al. (2019) notes challenges in effective implementation of lesson study, such as support for extended time, reliability of student outcomes and borrowing ideas from other contexts. The 
IJLLS 9,3

model is, however, not static and can be designed differently to address the specific contexts targeted for improvement (Holmqvist, 2017). Further, Dudley et al., 2019 argue for lesson study to be treated holistically, with angels of development and improvement at classroom and aligned with "meaning-oriented" teacher learning. It is thus more than a curricular and pedagogical intervention. Teachers benefit from trouble-shooting in a collaborative setting (Cunningham et al., 2015; Lewis et al., 2012) to modify teaching and enable understanding (Munthe et al., 2016). Changing practice in substantive ways is difficult and how to succeed is a neglected area (Timperley et al., 2007). Teachers' motivation and intrinsic will are key factors. Intrinsic motivation is fostered in contexts that meet three basic human needs: agency or self-determination, competence and human connection (Deci et al., 2001). A key assumption for learning cycles to be effective is three inter-related levels: the student, the teacher and the organization.

\section{Professional development in inclusive education and neurodevelopmental conditions}

Inclusion is a guiding principle worldwide, and teachers concur with the concept and agree that this means teaching all children within the regular classroom (Higginson and Chatfield, 2012). This responsibility demands deep knowledge and creativity in addressing the needs of all students. University programs for pre-service teachers lack specialized training for educating children with NDCs (Morrier et al., 2011; Scheuermann et al., 2003; Timperley et al., 2007). Pre-service teacher education programs do include content on teaching children with diverse needs (e.g. dyslexia, dyscalculia and language impairment), but preparation for teaching children with NDCs is insufficient (Corona et al., 2017; Higginson and Chatfield, 2012). Teachers also explicitly express lack of sufficient competence in this area (Barnhill et al., 2011; Bartonek et al., 2018). This is problematic because teachers are not knowledgeable enough for inclusion, and this might lead to hesitation in educating children with NDCs in regular schools. PD is important for the formation of positive teacher attitudes; perceptions of negative attitudes towards people with disabilities can create barriers for individuals in inclusive settings (Garrard et al., 2019). In a comprehensive review, Wong et al. (2015) identified evidence-based intervention practices for children with autism. They found gaps in the existing knowledge about intervention practices for children and youth with ASD. The research primarily focused on outcomes associated with core symptoms of ASD, e.g. social, communication and challenging behaviors. A narrow perspective and lack of holistic view over the learning context, might not improve inclusion fully. Kosko and Wilkins (2009) examined the relationship between general educators' number of PD hours, years teaching SEN students and self-perceived ability to adapt instructions for SEN students. They found that teachers need at least $8 \mathrm{~h}$ of PD over a long time to improve their self-perceived ability to adapt instruction to children with diverse needs. The World Health Organization has highlighted the need for raising awareness of service provision for individuals with NDCs (WHO, 2013), and much work needs to be done in the area of PD for teachers of these students (Alexander et al., 2015; Wong et al., 2015). Inclusion is nevertheless not an easy goal to achieve, and wherever national curriculums and inclusion goals are combined with the intention of meeting the many different needs of children, this can lead to the creation of demands full of contradictions, tensions and challenges for general schools. There are PD programs designed to bridge the gap between inclusion and actual classroom practice (Hinton et al., 2008; Higginson and Chatfield, 2012). Successful programs have "a whole school approach" where all staff in the school share values and have knowledge about the importance of adjustments and flexibility (Booth and Ainscow, 2002; Higginson and Chatfield, 2012). The collaborative model with provision for teachers to reflect on their own teaching and solve difficulties together has been effective for teaching children with ASCs (Ho et al., 2018). Despite promising results, PD opportunities with teaching strategies related to special needs are 
seldom offered to general education teachers (Crosland and Dunlap, 2012; Kosko and Wilkins, 2009). In Mutch-Jones et al.'s study (2012), they used an experimental design with a lesson study approach, with the aim of exploring an inclusive science classroom. Their results suggest that an intervention can increase educators' ability to set an instructional context and generate more accommodations for students with learning disabilities. More studies are needed to establish how teachers can reach competence and training needs to know how to address all learners (Parsons et al., 2011), especially in naturalistic settings for external and ecological validity (Crosland and Dunlap, 2012). Lesson study has shown potential in teachers' ability to create improved learning for their students (Dudley, 2013; Munthe et al., 2016). Nevertheless, research on the perspectives of lesson study and students with NDCs do not exist as far as the author has been able to discern.

\section{Teachers' self-efficacy}

Teachers are better equipped to cope and more willing to persist and persevere when they believe in their own capability (Bandura, 1977, 1997). A large body of research shows that teachers' self-efficacy is associated with student outcomes (Klassen and Chiu, 2010). Measurement of self-efficacy reflects upon particular contexts or domains (Bandura, 1997). Educational research uses different instruments for measuring self-efficacy, for example, Tschannen-Moran, Woolfolk Hoy and Hoy's Teachers Self-Efficacy Scale (2001); Skaalvik and Skaalvik's Teacher Efficacy $(2007,2015)$; and Bandura's Guide for Self-Efficacy Scales (2006). In a large-scale study, Klassen and Chiu (2010) modeled and examined the relationships between teachers' years of experience, characteristics, self-efficacy, job stress and job satisfaction. Their results showed how self-efficacy was influenced by years of experience in a nonlinear relationship. There is a lack of studies of self-efficacy measurements with a focus on teachers of students with ASD (Ruble et al., 2013), and even fewer focus on general teachers and students in need of special support. Previous researchers highlighted the instruments' validity weaknesses (Klassen et al., 2011) and fundamental understanding of the concept (Goddard et al., 2000). Self-efficacy beliefs are not static and are affected by environmental factors and personal attributes. Self-efficacy is a perceived level of ability and capability, and teachers will act after their beliefs about their capability (Bandura, 2012). Furthermore, in the complexity of the definition, researchers state that the concept is belief in one's capability to produce certain actions (perceived self-efficacy) and about convictions, not objective measures of actual actions or competence (Bandura, 1977; Goddard et al., 2000).

\section{Method \\ Participants and settings}

The study was conducted in a large-sized school district during a period of five months. The researcher recruited a diverse sample of teachers by sending inquiries to different schools within the same socio-economic area and geographical location near the placement of the researcher. Elementary and middle schools in the area were approached by the researcher sending information about the project. The two first schools declined and the three following schools accepted the request for participation. The principal or special needs teacher informed teachers of the program and the study. Informed consent was obtained from principals and the teachers. Alias names for the schools are West school $(n=7)$, City school $(n=7)$ and East school $(n=12)$. At two of the schools (West and City) the teachers evaluated a short version of the program (content of the program) before making a decision to participate or not. The principal at East school had both a top-down perspective, where the staff needed competence, and a bottom-up perspective, where the staff had asked for help regarding inclusion and diverse learners. Numbers regarding the demographics of the 


\section{IJLLS 9,3}

226

teachers or schools were not available, however all three participating schools came from the similar socio-economical environments. The recruitment process included finding as similar schools as possible within the geographical area, to make comparison possible. In total 26 teachers participated in this study, of 20 were female and six were male. Teachers reported years of experience in time-intervals and most teachers had more than 20 years of experience $(n=9)$, followed by between $11-15$ years of experience $(n=7)$. On average, all teachers had long experience of teaching. Mean age was level 4, between 11 and 15 years of experience. Only three teachers had between 1 and 5 years of experience. 17 teachers worked in elementary school and nine teachers worked in middle school. Elementary teachers were thus the largest professional group $(n=13)$, followed by subject teachers in middle school $(n=9)$. Other professions represented are principal, special needs teacher, pre-school teacher and language teacher.

\section{Procedure}

This mixed-methods study addresses teachers' knowledge and self-efficacy. A convergent mixed-methods design is used, a design in which qualitative and quantitative data are collected in parallel, analyzed separately and then merged (Figure 1, Creswell and Creswell, 2018). The method allows the comparison of different perspectives drawn from quantitative and qualitative data (Creswell, 2014). The measurement instrument in this study collected both quantitative (closed-ended) data and qualitative (open-ended) data to answer the research questions and hypotheses. As a complement, data collection via field notes was performed during intervention to deepen the understanding of participants' perception and position. Teachers also wrote down keywords and position statements during intervention, which were collected as a complement for analysis and evidence of learning. In the analysis, the different forms of data are integrated. At the end of the intervention, there was a follow-up interview for social validity. Before the intervention started, at baseline, the researcher investigated the current knowledge and self-perceived ability among participating teachers. The pre- and post-test was a questionnaire with both closed- and open-ended questions. Some of the variables are indexed and indicate the same theoretical concept. From previous research and an iterative process with research colleagues conducting similar research, an analytical tool was developed. For tool details, see the data analysis section.

\section{Construct of the intervention}

The research process followed a procedure with three basic steps. Step 1, construction of the program, was inspired by the key questions from Timperley et al.'s synthesis (2007, p. 27):

Figure 1.

The procedural diagram for the data collection, analysis and results (Creswell and Creswell, 2018). Figure derived from Creswell and Creswell (2018) 
Construct of the intervention The research process followed a procedure with three basic steps. Step 1, construction of the program, was inspired by the key questions from Timperley et al.s synthesis (2007, p. 27):

(1) What do teachers need to know to develop and deepen their professional understandings and extended skills to have a positive impact on student outcomes?

(2) What activities will provide teachers with necessary skills to promote learning for all students?

Goals and aims for the intervention were to be concrete and strongly linked to praxis. With this background, sensitivity and balance between theory, practice and inclusion were starting points for designing an appropriate and effective PD program. According to the selection of program content, teachers need to understand the needs and the unique learning characteristics of children with NDC. For construct validity (De Vaus, 2001), the author and two other researchers collected examples of indicators recognized as embodying what the concepts referred to (e.g. inclusive education, self-efficacy, modifications, skill and competence). The concepts are broad and one limitation in this study is all deviance and excluded cases for inequity, however we have gathered a good collection of cases to create a useful concept in this study (and similar studies by Peterson in progress). We presuppose that we have inspected not the full range of things covering the concepts used, but as much as required (Becker, 1998). The concept is not easy to measure, but with different aspects and mixed methods, the content validity in this study is adequate (De Vaus, 2001). The words and concepts in the questionnaire are within the meta-language well known for teachers. The questions were tested on teachers working at the same university as the author. The selection of the mode of professional development and the learning materials and list with possible modifications for children with NDC was based on theory and previous experience of practice. The program is based on following specific goals:

(1) Acquisition of more in-depth content knowledge

(2) Learning how to set and implement high functional modifications in the learning context

(3) Learning new concrete accommodations and new instructional methods to teach all students

(4) Developing capacity to teach to a variety of learning styles and challenging students

(5) Gaining theoretical background and understanding to increase student achievement and well-being

(6) Creating learning communities for discussion and reflection with colleagues and possibilities for feedback

In step 2, the empirical process continued with recruitment of schools. In all, three schools participated $(n=26)$. The intervention and lesson study cycles started at multiple baselines, where West school started in 2019, on the February 28 and ended on the March 21, City school started on March 23 and ended on May 2, and finally East school started on the April 2 and ended on May 14. Application of the program occurred within similar time spans. Sufficient time between administration of the pre-test and post-test strengthened the validity (De Vaus, 2001). The length of the gap was enough for participants not to remember their pre-test responses and at the same time provided this study with short- term effects. The lesson study cycles were held three times for

Teachers' capacity to create learning environments

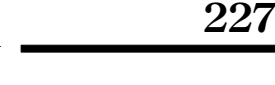




\section{IJLLS 9,3}

228

2 hours in each school in rooms set aside for the purpose, led by a facilitator, the researcher. In Step 3, all empirical data were sorted and analyzed and the effects and social validity of the program were measured.

\section{Description of intervention - independent variable}

As the objective stated, the PD program included technology, tools, processes and artifacts. The materials and structural components of the NDC AI program were developed within an iterative process with the researcher's network. Participating schools conducted a three cycle adapted Research Lesson Study model (Dudley et al., 2019) during one school term. (Figure 2). The cycles included material and strategies derived from evidence-based practices for teaching students with disabilities (e.g. explicit instruction, systematic instruction, peermediated instruction, accommodation of tasks, and curricula). There were no significant differences between the content and the topics among the participating schools. The same facilitator conducted all lesson study cycles. Each cycle of the intervention followed a fourstep process based on lesson study: study, plan, do and reflect (Lewis, 2015), except for the first session, where a longer introduction and pre-test were held. During the first cycle, teachers inventoried areas of improvement in their classrooms and teaching environments. Accommodations were then presented to the teachers, and modeled by the facilitator. Accommodations were presented, modeled and selected for their possibilities for enhancing inclusive education for children with NDCs. Teachers then discussed different modifications from the list with three potential development areas in teaching and adjusting the learning context: pedagogical area, psychosocial area, and physical area. Between cycle one and two, and two and three, teachers selected up to two accommodations suitable for their students and an area of improvement for the needs of their learners to conduct in practice. Additional data were collected with field notes on the areas of improvement for follow-up discussion at future sessions.

The four steps for cycle two and three were 1. Reflect and review, 2. Study/content presentation, 3. Plan for next accommodation, and 4. Prepare and do. During review, teachers evaluated and discussed their modification and adjustments in the learning context, reflecting on what worked well and what was challenging to implement. "Homework" was to read selected text and bring back notes with questions, criticisms, or new insights. The first text was a research-based text written for teachers with the content of executive functions published in a PD module, and the second text was by Steinberg (2018). The content of

Cycle 1

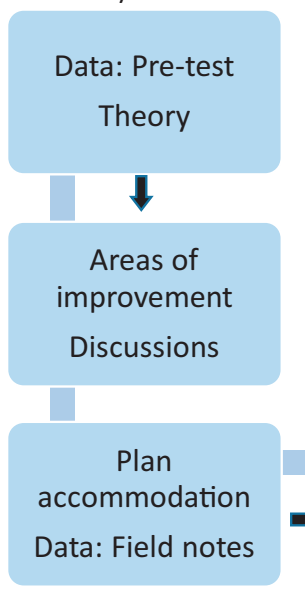

Cycle 2

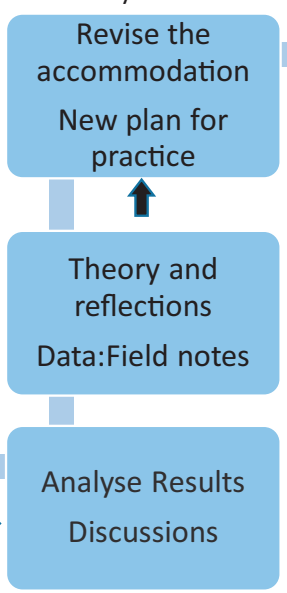

Cycle 3

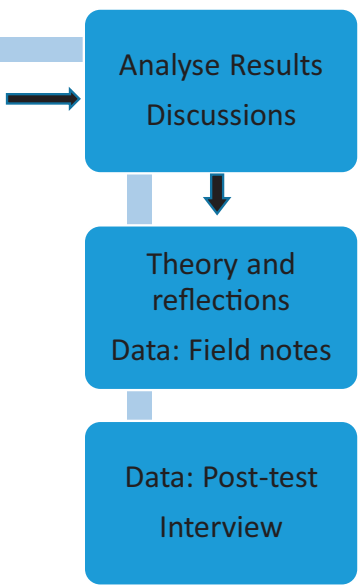

Figure 2.

The lesson study cycles in NDC awareness intervention (Figure derived from Dudley et al., 2019) 
Steinberg's text comprises examples of successful teaching and leadership in the classroom. The beginning of the text discussion and evaluation process began in smaller groups and ended with a larger discussion with the whole group. Next, the facilitator (author) led an interactive content presentation (35-50 min) with slides designed to build up teachers' knowledge within themes connected to inclusion, special needs and goals to daily teaching. The presentation consisted of relevant research and activities to a large extent connected with teachers' own classroom experiences. The presentation included visual models and experiences from working with special education. Guiding questions for discussion during content presentation were, for example: What is inclusion, and how do you see traces of inclusion in this school? Whose responsibility is inclusion and how do we work preventively? How can we strengthen the whole school approach? What modifications work in my classroom and why? During the third segment, practice, teachers integrated new knowledge into their instructional practices. Teachers discussed successful modifications and accommodations conducted in their practice, as well as implementations of revised modifications. During the last phase, preparation, the new homework was discussed and teachers made decisions for the next adjustments, that is, the same modification but more intense or a new or alternative modification. The facilitator presented concrete accommodations and evidence-based strategies for teaching students with NDCs. Throughout the whole program, connections were made with teachers' own classroom experiences, and opportunities for questions and feedback were provided. The variety of activities all aimed to develop teachers' understanding of the relationship between their teaching and student learning and increased inclusion. Teachers finally inventoried their potential modifications from a list: What do I do today and what can I start with or intensify? The program ended with the post-test and follow-up interviews.

\section{Variables}

The questionnaire included descriptive data and characteristics followed by three measures: a six-item teachers' self-efficacy scale with a four-point Likert scale (disagree, agree a little, agree and agree a lot), open-ended questions, and a case student. The case student was a description of a student with NDC and the question was how to adjust the environment for enhanced learning. The quantitative variables were teachers' estimation of self-efficacy, and whether in need of PD regarding the focus area. The items were derived from Bandura's theoretical and domain-focused guidelines $(1997,2006)$. The Likert scale responses were derived from TISES (Brouwers and Tomic, 2001). Measures of self-efficacy used with special educators include the Teacher Efficacy Scale and the Teacher Interpersonal Self-Efficacy Scale (TISES). The TISES is a 24-item questionnaire with a 6-point Likert-type scale ranging from strongly disagree to strongly agree (Brouwers and Tomic, 2001). The following variables have been indexed to descriptions of the concept, self-efficacy and self-perceived ability: I have enough competence to teach children with neurodevelopmental conditions, I have enough competence to adjust the learning context for children with neurodevelopmental conditions, and I know many concrete and valuable accommodations that work well for children with neurodevelopmental conditions. Reliability analysis with Cronbach's alpha, average covariance over three variables; $a=0,80$. The scale and measuring construct are reliable (Field, 2013). The reliability test showed large homogeneity between variables and strong correlation between the items intended to measure self-efficacy. An additional variable for measuring self-efficacy was I need professional development to meet and teach children with neurodevelopmental conditions.

\section{Pedagogical content knowledge measures}

Teacher knowledge and width in responses according to inclusive education were measured using open-ended questions and a case student. The open-ended questions are categorized
Teachers' capacity to create learning environments

229 


\section{IJLLS 9,3}

\section{0}

Table 1.

Outcome measure, difference between baseline and post-intervention in teachers' responses after three themes in the learning context, the pedagogical, the psychosocial and the physical. The categories are derived from Küller's model (1991), The Human-Environment-Interaction Model. In Küller's model, the pedagogical area includes the tasks and activities for learning; the physical includes the organization of rooms and facilities, light, sound and acoustics; and the psychosocial area includes atmosphere, social composition, sense of coherence and treatment. The model aligns with the pragmatic approach, where we construct our own sense of reality and that is formed by our experience of the environment. The organism acts in accordance with its surroundings (Dewey, 1963). Teachers were also asked to write down different adjustments for a student with NDC. This was presented as case student at the end of the questionnaire. Case students are sometimes used in lesson studies. Case students represent learner groups whom it is important to understand. Teachers plan for the whole group but keep specific focus on the case students at key points in the lesson (Dudley, 2013). Qualitative variables were quantified by counting themes in teachers' responses. Responses from each school were first analyzed separately, and all schools were merged together for the final result.

\section{Procedures for data collection and data analysis}

The methods used for data collection were teacher questionnaires and field notes during observation. Time between pre-test and post-test was six weeks on average, which was long enough to avoid threats to reliability. Field notes from discussions and reflections during intervention constituted a complementary data collection. The data were collected by the author and the data analysis was made in collaboration with two other researchers. Figure 1 shows the procedure for data collection, analysis and results. The data analysis in this study used phases from a convergent mixed-methods design (Creswell and Creswell, 2018). First, the quantitative database was analyzed in terms of statistical results. Second, the qualitative database was analyzed by coding the data and collapsing the codes into broad themes. Third, a mixed-method data analysis was conducted by integrating the two databases and merging the results from both the quantitative and qualitative findings (Creswell and Creswell, 2018, p. 220). Pre-intervention levels were examined and then compared with post-intervention scores via a non-parametric test, the Wilcoxon signed-rank test (Field, 2013). See Table 3 for Wilcoxon test. Separate analysis between schools were conducted to explore differences among cohorts. See Table 1. To determine if cohorts differed on initial baseline measures, analyses of variance (ANOVAs) were conducted on all quantitative pre- and post-test

\begin{tabular}{lcccc}
\hline Measure & Difference & Mean $^{\mathrm{a}}$ & SD & Range \\
\hline Pedagogical area & & & & \\
West school & 12 & 18.7 & 6.79 & \\
City school & 16 & & & \\
East school & 28 & & & \\
Psychosocial area & & 14.33 & 6.54 & \\
West school & 15 & & & \\
City school & 6 & & & \\
East school & 22 & 8 & 3.74 & \\
Physical area & & & & \\
West school & 3 & & & \\
City school & 9 & & & \\
East school & 12 & & &
\end{tabular}

Note(s): ${ }^{a}$ Mean is mean difference between baseline and post-intervention with merged cohorts and within each category 
measures of teachers. The analyses of variance with ANOVA between schools in the quantitative variables showed enough competence (3.5\% pre-intervention vs. $6.5 \%$ postintervention), adjusting the learning context (12 vs. $5.1 \%$ ), concrete modifications (8.9 vs. $9.0 \%$ ), need for PD (1.9 vs. $8.9 \%$ ) and number of modifications (9.9 vs. $10.55 \%)$. Because $p$-values showed no significant difference between schools, merging was verified as reliable. Factor analysis for measurement of the items showed 61.35 (SPSS, version 25). The result from the component analysis shows that the variables substantially measure the same underlying dimension. The questions thus show reliability and satisfactory measurement of the concept of self-efficacy. Values over 0.6 have the required qualities (Sharma, 1996).

\section{Ethical considerations}

This research project followed the ethical guidelines stated by the Swedish Research Council for research in social science (Vetenskapsrådet, 2002). The research strictly followed the requirements for information, consent, confidentiality and use. Teachers and principals received information about the study and the purpose as well as information about time, setting and data collection. When schools accepted to participate in the professional development program, all participants signed the agreement consent. The participants' individual identity and participating schools were kept confidential during the research process.

\section{Results}

Measurements of readiness to prepare the learning environment were made using categories and examples teachers gave in three different areas of the learning context (pedagogical, psychosocial and physical). Pre-intervention examples were thematically coded and compared with post-intervention outcomes. The variables were quantified. The overall result showed an increase in all areas from baseline to post-intervention. Raw data for these assessments are presented in the Appendices. After completing all three lesson cycles teachers' responses were more variated. In addition, new categories of accommodations were found. In the pedagogical area categories increased from 110 to 159, in the physical area the categories increased from 46 to 70 , and in the psychosocial area from 42 to 84 . The total increase in the pedagogical area was $44.5 \%$, physical area $52.2 \%$ and psychosocial area $100 \%$. Table 1 shows the mean difference between schools and areas and between baseline and post-intervention. Table 2 shows results after merging the schools. Table 3 shows results from the self-efficacy questionnaire, e.g. the paired-samples $t$-test, comparing self-efficacy prior to and following participation in the NDC AI intervention. Table 4 is the Wilcoxon test. Effect sizes and $t$ - and $p$-values were calculated with SPSS, version 25, and at www.uccs.edu and www.socscistatistics.com. Scores on the self-efficacy questionnaire were significantly higher following the training in all items, e.g. I have enough competence $(M=2.65, \mathrm{SD}=0.629)$ than prior to participation $(M=2.08, \mathrm{SD}=0.668)$.

\section{Designing for inclusion}

Teacher knowledge and capacity to create inclusive learning environments. Field notes on teachers' choices for implementing modifications in the learning context between cycles provided summaries for the choices in each area: 12 teachers chose to adjust something in the pedagogical area, 11 teachers chose the psychosocial area, and three teachers chose the physical area. Initial perceptions from some of the teachers showed a lack of perspective, where prerequisites are seen as missing. At the end of the program, teachers showed more confidence and openness to possibilities for small changes in the environment. Analysis of qualitative data showed that teachers' positions changed during the process, from describing

\section{Teachers'} capacity to create learning environments \\ 231}




\section{IJLLS \\ 9,3}

\begin{tabular}{|c|c|c|c|c|c|c|}
\hline Measure $(n=26)$ & Mean & $\mathrm{SD}$ & Range & Effect size (Cohen's $d$ ) & $t$-value & $p$-value \\
\hline \multicolumn{7}{|l|}{ Pedagogical area } \\
\hline Baseline & 39.66 & 2.9 & 4 & 3.90 & 14.0796 & $<0.001$ \\
\hline Post-intervention & 58.36 & 6.12 & 13 & & & \\
\hline Difference & 18.7 & 6.79 & 16 & & & \\
\hline \multicolumn{7}{|l|}{ Psychosocial area } \\
\hline Baseline & 14.00 & 2.84 & 6 & 2.70 & 9.7443 & $<0.001$ \\
\hline Post-intervention & 28.33 & 6.94 & 16 & & & \\
\hline Difference & 14.33 & 6.54 & 7 & & & \\
\hline \multicolumn{7}{|l|}{ Physical area } \\
\hline Baseline & 15.66 & 6.18 & 12 & 1.30 & 4.6901 & $<0.001$ \\
\hline Post-intervention & 23.66 & 6.12 & 15 & & & \\
\hline Difference & 8.00 & 3.74 & 9 & & & \\
\hline
\end{tabular}

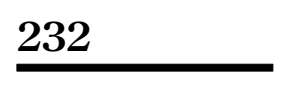

Table 2.

Outcome measure of teachers' responses at pre- and post-

intervention all schools merged

\begin{tabular}{lrrcrr}
\hline Measure $n=26$, (item 4a - d) & Mean & $S D$ & Cohen's $d$ & $p$-value & $t$-value \\
\hline $\begin{array}{l}\text { I have enough competence } \\
\text { Baseline }\end{array}$ & 2.08 & 0.668 & & & \\
$\begin{array}{l}\text { Post-intervention } \\
\text { Competence to adjust the learning context }\end{array}$ & 2.65 & 0.629 & 0.878 & $<0.000$ & -4.18 \\
$\begin{array}{l}\text { Baseline } \\
\text { Post-intervention }\end{array}$ & 1.88 & 0.771 & & & \\
$\begin{array}{l}\text { I know many concrete accommodations } \\
\text { Baseline }\end{array}$ & 2.50 & 0.583 & 0.953 & $<0.000$ & -4.500 \\
$\begin{array}{l}\text { Post-intervention } \\
\text { Ineed professional development }\end{array}$ & 2.85 & 0.710 & & & \\
$\begin{array}{l}\text { Baseline } \\
\text { Post-intervention }\end{array}$ & 3.13 & 0.613 & 0.934 & $<0.000$ & -4.924 \\
& 2.67 & 0.761 & 0.590 & $<0.002$ & 3.412 \\
\hline
\end{tabular}

\section{Table 3.}

Self-efficacy variables Outcome measures of teachers' self-efficacy. Based on the 4-point Likert scale

\begin{tabular}{lcc}
\hline & $Z$-score & $\begin{array}{c}\text { I Asymp. Sig } \\
\text { (2-tailed) }\end{array}$ \\
\hline I have enough competence to teach children with NDC & $-3.217^{\mathrm{a}}$ & $<0.001$ \\
I have enough competence to adjust the learning context for children with & $-3.358^{\mathrm{a}}$ & $<0.001$ \\
NDC & & $<0.000$ \\
I know many concrete and valuable accommodations for children with & $-3.557^{\mathrm{a}}$ & $<0.005$ \\
NDC & $-2.840^{\mathrm{b}}$ & \\
I need professional development to meet and teach children with NDC & & \\
Note(s): ${ }^{\text {Based }}$ on negative ranks. ${ }^{\mathrm{b} B a s e d ~ o n ~ p o s i t i v e ~ r a n k s ~}$ &
\end{tabular}

poor pre-requisites and lack of time to a more positive standpoint with insights into the importance of even very small changes and adjustments. Teachers' instructional planning adaptation for students with NDCs rose from its initial value.

Pedagogical area. Two completely new concrete modifications were found in this area postintervention: positive reinforcement and working with a rewards system. Teachers mentioned 
more preparation for transitions and transition support (from 35\% pre-intervention to $77 \%$ post-intervention). Small transitions and horizontal transitions are changes within the school day (e.g. from one activity to another and from classroom to playground). Elementary and middle school settings include many transitions throughout the day. The teachers broadened their understanding of the importance of support for children before and during transitions. Other improvement areas of modifications for the students were compensatory aids, opportunities for breaks, adjustments in tasks and repetition for working memory problems. Clear instructions, structure and visual support were other areas that showed increases in the teachers' responses.

Psychosocial area. In the psychosocial area, there were three completely new adjustments in the learning context: additional confirmation, diversions for managing difficult behavior, and involving the interests of students for strengthening desirable behavior like on-task focus and motivation. Further areas of improvement were especially strengthening the relationship between teacher and student (from $12 \%$ to $46 \%$ ), teacher support when dividing classes into pairs and groups, and positive reinforcement. Teachers reflected on the more usual negative attention and decided to change this pattern. Building on the interest of students is important for developing abilities for students with NDCs. This can lead to positive effects in not only the psychosocial area with communication and interaction, but also in the pedagogical area. This was another area of development for teachers.

Physical area. Regarding the facilities and what can be adjusted in the physical environment, two new accommodations for students were found in the teacher responses: finding a retreat place or room and support at lunch time. Other areas significantly more represented in responses were careful thinking when considering placements for students (from $30 \%$ to $58 \%$ ), stimuli-sanitizing the environment (from $58 \%$ to $77 \%$ ), and making small group arrangements. Stimuli-sanitizing refers to distracting artifacts in the physical environment (e.g. noise, tidiness, decoration, furniture and rooms). The school facilities were among teachers' challenges for inclusive education. Preparing the physical environment enhances participation, and by removing what students might find disturbing, on-task behavior increases. When designing a learning environment, it is crucial to thinking about sensory issues to meet all needs. A good sensory design has a calming effect, and the design of a school is essential for suiting unique sensory challenges.

Case student. In the questionnaire, teachers wrote down how to adjust the environment for a student with a NDC. The number of accommodations that teachers identified for the student profiled in the assessment rose from its initial value. Teachers' responses and total number of accommodations for the case student increased for 23 out of 26 participants $(88 \%)$. Two participants had the same amount at pre- and post-test and one participant decreased from five to three modifications. An outlier was the special needs teacher who gave 14 themes of accommodations in the baseline but also increased the amount to 15 themes at postintervention. The largest change and effect in measurement of teachers' responses in this outcome measurement was from two accommodations to seven. The student case is concrete, therefore making it easier for teachers to respond to this particular question. The lesson study cycle included this specific area to implement, evaluate and improve modifications in the learning environment. Teachers mentioned the one-on-one instruction, and the lack of time when serving large groups, as an explanation for why this method was not used as often as recommended. Teachers expressed a need to have more time explicitly dedicated to conducting one-on-one instructional sessions with students.

\section{Teachers' self-efficacy}

No teacher estimated themselves as competent enough when it comes to teaching children with NDCs. In the same manner, no teacher estimated not in need of professional development in the area. $73 \%$ of the teachers estimated in great need of competence development before the
Teachers' capacity to create learning environments

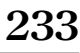


IJLLS 9,3

intervention. $46 \%$ rated in great need of PD after the program. Teachers' perceived selfefficacy increased after the program. Mean increase in self-efficacy was $50 \%$. The variables; $I$ have enough competence to teach children with NDC, I have enough competence to adjust the learning context and I know many concrete and valuable modifications for children with NDC are indexed in SPSS and the new variable, self-efficacy had a maximum value of 12 and a minimum value of 3 . Pre-intervention mean was 6.19 and post-intervention mean was 8 . At post-intervention, one participant had the maximum of 12 and three participant had the value 10. At pre-intervention, the highest value was 9 . Further items to answer the research question, I have enough time to support and prepare the learning context for children with NDC and I need professional development showed a small increase in estimating having time and a larger change in the need of PD to teach children with NDC.

\section{Discussion}

This study aimed to examine the efficacy of a short PD program designed and adapted from lesson study, to support and assist elementary and middle teachers in adjusting the learning environment for classroom diversity. The initial evidence suggests that a short program may be a starting point and a promising way to engender meaningful changes in teacher knowledge, self-efficacy and beliefs. The main findings in this study show that collaborative learning environments, with opportunities to develop more content knowledge and special didactic knowledge, in order to become more prepared for teaching students with NDC is beneficial for teachers. Schools can facilitate modified lesson study cycles for developing teachers' learning. The key features of the current program are based on rigorous research for teachers' development and children with NDC. The development trajectory is how to effectively support these children in mainstream classrooms. It appears that having the opportunity to participate in a PD program and in a professional community in practice is valuable (Timperley et al., 2007); even though a long-term program is preferred, a shorter version is a good start. Prior studies have noted the importance of closing the gap between theory and practice when it comes to PD (Marton and Tsui, 2004). The preparation for inclusive education is insufficient in pre-service teacher programs (Morrier et al., 2011; Scheuermann et al., 2003) and among pre-service and in-service teachers (Bartonek et al., 2018); therefore, this study aimed to examine the effect of a time- and cost-effective PD program. The findings from this PD for teachers show effective change that can make a positive difference in learning levels for students with NDCs in inclusive schooling environments. The results, showing increased understanding of diverse student's learning and beliefs in students' capacity when given the right support, is in line with large-scale lesson study projects (Dudley et al., 2019). However, the changes to more inclusive education are no "quick fix" or technical training, although schools will benefit from developing internal small collaborative research communities. Special needs teachers can be the facilitators. A more pragmatic approach will make the teachers the instigators and engage them with evidence-based programs that support inclusive education. This PD program is not longterm, but it showed significant changes in all areas of the school context. The largest effect was seen in the case student, with substantial improvement, which is of great value and has promise as a means for addressing the needs of the children these teachers serve. This increase in accommodations is in line with the results from Mutch-Jones et al. (2012). Paying attention and responding to students with special needs by creating concrete accommodations was a catalyst for making changes. Additionally, these changes can have an impact on inclusion and students' well-being. Awareness of the disadvantages for students with NDC, as well as knowing more appropriate accommodations make teachers more prepared for teaching diversity (Wong et al., 2015). The aim of this study was to evaluate the PD program and teacher learning, not the teacher. Teachers are assumed to do their best 
every day to prepare the learning context and meet all needs of their students. This research was driven by a desire to enhance and strengthen teachers' knowledge to establish understanding and more advantageous situations for learning. Teacher learning is the primary subject of this study and findings. The result showed improved ability to understand the students' needs within three areas. The increase in the psychosocial area, with teachers taking deeper responsibility for strengthening the relationship is important for students' well-being (Humphrey and Symes, 2010). The second research question aimed to answer perceived self-efficacy, which is important for self-confidence and the ability to rely on capacity and skills. When you trust your ability, motivation is enhanced. Teachers are also learners, and increasing their self-efficacy improves their motivation for inclusive education (Bandura, 2012; Donohoo, 2018). Competence and skills are difficult to measure, although this study attempted to do that without measuring student outcomes. Self-ability and reflection constitute the ground where readiness starts. Agency and competence, as human needs, are important for action (Deci et al., 2001). Teachers in mainstream classrooms can improve academic achievement and well-being among students when they have more knowledge about how to prepare and adjust the learning environment (Dudley, 2013). This is particularly essential for children with SENs (Hattie, 2013; Larcombe et al., 2019). During the program, some teachers transitioned from having a categorical perspective where the student owns his or her difficulties, to a deeper understanding of the importance of the environment and teacher preparation. A proactive approach with school systems change initiatives, have more potential for improving inclusion (Crosland and Dunlap, 2012). Teachers expressed placing a great value on getting together to discuss inclusive education. This is of great importance according to Timperley et al. (2007): "Typical sequences involved a rationale or catalyst to engage, instruction in key theoretical principles, and then opportunities to translate theory into practice and deepen understanding of theory." The closeness to practice was highlighted by the principles as being of great significance. Teacher manuals and instructional material can be good, but teachers need opportunities to discuss, reflect and try out new approaches in practice, and improvement is more beneficial when they collaborate (Holmqvist, 2017; Lewis et al., 2012; Timperley et al., 2007). A collegiate ethos with collaboration and more professionalism will benefit inclusive education. Future studies that train teachers to implement evidence-based interventions for students with diverse characteristics are needed (Munthe et al., 2016; Watkins et al., 2019). Teachers' perceived self-efficacy regarding their capacity for preparing and adjusting the learning context showed significant change in this study. After the program, teachers reportedly felt that they knew how to make more concrete and valuable modifications for students, which increases the chances for implementation. The teachers had many years of experience, but still most of them expressed a need for more competence in this area. This is in line with a recent large-scale investigation (Bartonek et al., 2018). Self-efficacy leads to increased self-trust and action, and new knowledge leads to operation and movement (Dewey, 1963). Self-confidence reinforces the profession. Small changes can have a major effect on learning, and it is essential that teachers are aware of this. Staffing and teamwork are key issues for making inclusion happen, both inside and outside the classroom. Teachers are expected to contribute to school development and stay up to date on research. To engage in PD and follow requests about participating in school development and improvement, teachers need organizational conditions and support to do so (Fontil et al., 2019; Timperley et al., 2007). In the study by Kosko and Wilkins (2009), teachers need $8 \mathrm{~h}$ of $\mathrm{PD}$ to raise self-efficacy; in this study, results showed that $6 \mathrm{~h}$ during a four-month period is also effective. Business as usual will not change the situation in schools for less privileged students. School management has a crucial role in providing teachers with support, PD opportunities and finally, yet importantly, time for preparation. During the first session, some teacher expressed an attitude of not needing theory or background information. At the same time, $73 \%$ of the teachers expressed that they needed PD regarding inclusive education.
Teachers' capacity to create learning environments

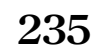


IJLLS 9,3

Results in Klassen et al. (2011) indicate that more experience improves self-efficacy. The complexity of designing optimal learning environments for students with NDCs can explain the findings from this study. All teachers expressed a need for more competence. Theory is the foundation for understanding and covering all the diversity in SENs. Timperley et al. (2007) call these problems with over-assimilation, when new information is perceived as congruent, although it is actually dissonant. Only classroom observations can tell how well the learning environment is prepared to meet the needs of all students. The results of this study show enhanced readiness and self-efficacy, which increases opportunities for academic success for all children. The next question is for teachers to ask how effective the PD program was, what they have achieved, and how to prepare the learning environment further to promote students' learning and well-being. Teachers are highly motivated when they have identified a problem in the teaching context. An urgent problem generates performance and alertness (Dewey, 1916). When we encounter a previously unknown problem, we search for an appropriate response and, through experimentation, we acquire new habits (Biesta, 2007). In the PD program with problems and inquiry grounded in teachers' practice, teachers developed the acquisition of knowledge as a result of actions. Teachers' increased awareness of the need of support when dividing classes into peers and groups will reduce peer and group difficulties. The teachers also mentioned the importance of establishing a good relationship. High-quality student-teacher relationships are important for academic and social development. Positive reinforcement builds on and strengthens student potential rather than student difficulties, and it is beneficial for the students' social position in the group.

The move towards inclusion in education is not only about minorities, even though the focus in this PD was children with NDC. Inclusion means a better education for all children. All children start school with expectations and dreams. As a public institution, the school is responsible for making dreams come true and develop the full range of abilities and interests in young people. Intervention design in educational research poses several questions to the researcher, including whether a particular intervention is desirable, about the educational effects of the actions taken, and how the intervention can benefit participants (Biesta, 2007). Education is a moral rather than a technical practice, and researchers need to consider the potential educational value and the opportunities for learning that follow the actions of interventions. Biesta (2007) draws parallels to Aristotle and his distinction between practical wisdom (phronesis) and instrumental knowledge (techne). A well-designed PD program can provide teachers with more knowledge, wisdom and self-efficacy. The teachers' beliefs in their capability raised in this study. Self-efficacy is the self-regulation of motivation and action (Bandura, 2012). In addition, knowledge can create a more human-focused and flexible school system. The achievement gap between students of more advantaged prerequisites and their less privileged peers is often discussed. Bridging the gap is an essential goal for elementary and middle schools. Unfortunately, we know there is still much to improve for enhancing inclusive education and the right for all individuals to grow, learn and develop valuable skills for the future. The findings of this study suggest that a three-session PD model can support general teachers in developing broader knowledge and enhanced self-efficacy. Self-confidence can reduce teacher stress (Corona et al., 2017) and help teachers to perceive students with NDCs as learners with a lot of potential rather than students with challenging behavior (Donohoo, 2018; Donohoo and Katz, 2017). Evidence on inclusive classrooms shows that successful implementation of inclusion strategies can lead to increased social involvement, personal well-being, and higher academic performance, compared with segregated school settings (Linton, 2015). Teachers' knowledge about how to support all students has a bearing on how they interact and accommodate in practice. Teachers in general classroom can develop an understanding of their role and responsibility for all students' outcome. This intervention created opportunities for collaborative learning (Ho et al., 2018; Lewis et al., 2012). Inclusive education is a good learning and teaching 
environment. A learning-friendly environment is both child friendly and teacher friendly (UNESCO, 2005, p. 4). It places the child in the center and gives teachers the best preconditions to create and give children the best education possible.

\section{Strengths and limitations}

This study had three participating schools; for a more reliable result, large-scale research is recommended. Important constraints for implementation have been analyzed, and the program is sustainable. In the future, the program can include more rigorous content and more adjustments for all levels, as well as more participants in each school for making "the whole school approach" possible. Another limitation is the level of measurement, and translating what is learned into an individual's particular teaching content is more advantageous. It is worth exploring in future research the actual implementation of accommodations, as well as listening to the students' perceptions of the learning environment. However, this study did not attempt to measure and evaluate students' learning. Future studies could address students' learning as a next step. Furthermore, the effectiveness could also be measured after a time-span for evaluating long-term effects. The concept of self-efficacy is measured with a narrow perspective, however, the indexed variables give the concept a good explanation. There is a small gender bias in this study $(78 \%$ females), which is not ideal for a sample, but female teachers dominate elementary school settings. The golden standard for experimental design with a control group is not always possible in educational research. In this study, no teachers were available for a control group. We cannot be certain what factors have produced the change; any change can be due to unknown factors that occurred between the sessions. This design with comparison groups can, however, strengthen the effects of the actual program. Some parts of the program have an individual perspective, but inclusive education and participation are highly dependent on the group and surroundings. In the future, programs should focus more equally on the individual and the group because both perspectives are important. The responsibility for inclusive education is each teacher's, together with his or her colleagues and school management, which is the key concept in the NDC AI program. This small-scale research project and preliminary results raises interesting points about elementary and middle school teacher training to improve inclusive education.

\section{Future implications}

The results of this study have implications for practitioners teaching students with NDC. Teachers need a broad repertoire of strategies to determine and prepare for teaching all students. The findings of this study have implications for teachers' design and delivery of educational support to students with NDC. The findings also provide guidance to educators and leaders concerning how to strengthen teachers' awareness and readiness for teaching students with NDC in general classrooms.

\section{Conclusions}

The NDC awareness program was successful. Generally, teachers became more knowledgeable about NDCs and appropriate concrete modifications. The result also showed enhanced self-efficacy according readiness and to teach children with NDC. Teachers understood the necessity of preparing the environment and knew more accommodations to include children with NDC, which is positive for the whole cluster and any diverse needs. Sustainable professional development with modified lesson study cycles, can assist teachers in their practice. Teachers in regular classrooms indicate a need of more competence according to teach children with special needs. Teachers' learning in lesson study cycles may 
$\underset{9,3}{\text { IJLLS }}$

properly prepare teachers for diversity in the classroom. The author recommend time- and cost effective PD programs like NDC AI for general teachers.

\section{References}

Al Otaiba, S. and Fuchs, D. (2006), "Who are the young children for whom best practice in reading are ineffective? An experimental and longitudinal study", Journal of Learning Disabilities, Vol. 39 No. 5, pp. 414-31.

Alexander, J.L., Ayres, K.M. and Smith, K.A. (2015), “Training teachers in evidence-based practice for individuals with autism spectrum disorder: a review of the literature", Teacher Education and Special Education, Vol. 38 No. 1, pp. 13-27.

Artiles, A. and Waitroller, F. (2013), "A decade of professional development research for inclusive education: a critical review and notes for a research program", Review of Educational Research, Vol. 83 No. 3, pp. 319-356.

Artiles, A., Harris-Murri, N. and Rosenberg, D. (2006), "Inclusion as social justice: critical notes on discourses, assumptions and the road ahead", Theory Into Practice, Vol. 45 No. 3, pp. 260-268.

Bandura, A. (1977), "Self-efficacy: toward a unifying theory of behavioural change", Psychological Review, Vol. 84, pp. 191-215.

Bandura, A. (1997), Self-efficacy. The Exercise of Control, Freeman, New York.

Bandura, A. (2006), "Guide for constructing self-efficacy scales", in Pajares, F. and Urdan, T. (Eds), Self-efficacy Beliefs of Adolescents, Information Age Publishing, Charlotte, NC, pp. 307-337.

Bandura, A. (2012), "On the functional properties of perceived self-efficacy revisited", Journal of Management, Vol. 38 No. 1, pp. 9 -44.

Barnhill, G.P., Polloway, E.A. and Sutmutka, B.M. (2011), “A survey of personnel preparation practices in autism spectrum disorders", Focus on Autism and Other Developmental Disabilities, Vol. 26 No. 2, pp. 75-86.

Baron-Cohen, S. (2017), "Editorial perspective neurodiversity - a revolutionary concept for autism and psychiatry", Journal of Child Psychology and Psychiatry. Vol. 58 No. 6, pp. 744 -747.

Bartonek, F., Borg, A., Berggren, S. and Bölte, S. (2018), Inkluderingsarbete för barn och ungdomar vid svenska skolor: en kartläggning bland 4778 anställda vid 68 skolor, Center of Neurodevelopmental Disorders at Karolinska Institutet (KIND), Stockholm.

Becker, H. (1998), Tricks of the Trade: How to Think about Your Research while Youre Doing it, The University of Chicago Press, London.

Biesta, G. (2007), “Why 'what works' won't work: evidence-based practice and the democratic deficit in educational research", Educational Theory, Vol. 57 No. 1, pp. 1-22.

Bölte, S., Girdler, S. and Marschik, P.B. (2018), "The contribution of environmental exposure to the etiology of autism spectrum disorder", Cellular can Molecular Life Sciences, Vol. 76 No. 7, pp. 1275-1297.

Booth, T. and Ainscow, M. (2002), Index for Inclusion: Developing Learning and Participation in Schools, Centre for Studies in Inclusive Education, Bristol.

Bottema-Beuel, K., Malloy, C., Cuda, J., Yoon Kim, S. and Paquette MacEvoy, J. (2019), "Friendship expectations may be similar for mental age-matched children with autism spectrum disorder and typically developing children", Journal of Autism and Developmental Disorders, No. 49, pp. 4346-4354, doi: 10.1007/s10803-019-04141-7, (Accessed 18 January 2020).

Brouwers, A. and Tomic, W. (2001), "The factorial validity of scores on the teacher interpersonal selfefficacy scale", Educational and Psychological Measurement, Vol. 61 No. 3, pp. $432-445$.

Corona, L., Christodulu, K. and Rinaldi, M. (2017), "Investigation of school professionals' self-efficacy for working with students with ASD: impact of prior experience, knowledge, and training", Journal of Positive Behavior Interventions, Vol. 39 No 2, pp. 90-101. 
Creswell, J. and Creswell, D. (2018), Research Design: Qualitative, Quantitative and Mixed Methods Approaches, 5th ed., SAGE Publications, Thousand Oaks. CA.

Creswell, J. (2014), A Concise Introduction to Mixed Methods Research, SAGE Publications, Thousand Oaks, CA.

Crosland, K. and Dunlap, G. (2012), "Effective strategies for the inclusion of children with autism in general education classrooms", Behavior Modification, Vol. 36 No. 3, pp. 251-269.

Cunningham, A., Etter, K., Platas, L., Wheeler, S. and Campbell, K. (2015), "Professional development in emergent literacy: a design experiment of Teachers Study Groups", Early Childhood Research Quartely, Vol. 31, January, pp. 62-77.

De Vaus, D. (2001), Research Design in Social Research, SAGE Publications, London.

Deci, E.L., Koestner, R. and Ryan, R. (2001), "Extrinsic rewards and intrinsic motivation in education: reconsidered once again", Review of Educational Research, Vol. 71, pp. 1-27.

Dewey, J. (1916), Democracy and Education, The Free Press, New York.

Dewey, J. (1963), Experience and Education, Collier Macmillan, New York.

Donohoo, J. and Katz, S. (2017), "When teachers believe, students achieve", The Learning Professional, Vol. 38 No. 6, pp. 20-27.

Donohoo, J. (2018), "Collective teacher efficacy research: productive patterns of behaviour and other positive consequences", Journal of Educational Change, Vol. 19 No. 3, pp. 323-345.

Dudley, P., Xu, H., Vermunt, J.D. and Lang, J. (2019), “Empirical evidence of the impact of lesson study on students' achievement, teachers' professional learning and on institutional and system evolution”, European Journal of Education, Vol. 54, pp. 202-217.

Dudley, P. (2013), "Teacher learning in Lesson Study: what interaction-level discourse analysis revealed about how teachers utilized imagination, tacit knowledge of teaching and fresh evidence of pupils learning, to develop practice knowledge and so enhance their pupils' learning", Teaching and Teacher Education, Vol. 34, pp. 107-121.

European Agency (2014), Raising the Achievement of All Learners in Inclusive Education, Brussels, available at: https://www.european-agency.org/projects/raising-achievement-all-learnersinclusive-education.

Field, A. (2013), "Discovering statistics using IBM SPSS statistics”, SAGE Publications, London.

Fontil, L., Gittens, J., Beaudoin, E. and Sladeczek, I. (2019), "Barriers and facilitators of successful early school transitions for children with autism spectrum disorder and other developmental disabilities: a systematic review", Journal of Autism and Developmental Disorders, Vol. 26, pp. 1-16.

Fullan, M. and Hargreaves, A. (1996), What's Worth Fighting for in School?,Teachers College Press, New York.

Garrard, T.-A., Christopher, R. and Pedersen, S. (2019), "Attitudes of Australian primary school teachers towards the inclusion of students with autism spectrum disorders", Journal of Research in Special Educational Needs, JORSEN, Vol. 19 No. 1, pp. 58-67.

Goddard, R., Hoy, W. and Woolfolk Hoy, A. (2000), "Collective teacher efficacy: its meaning, measure and impact on student achievement", American Educational Research Journal, Vol. 37 No. 2, pp. 479-507.

Godfrey, D., Seleznyov, S., Anders, J., Wollaston, N. and Barrera-Pedemonte, F. (2019), "A developmental evaluation approach to lesson study: exploring the impact of lesson study in London schools", Professional Development in Education, Vol. 45 No. 2, pp. 325-340.

Hargreaves, D. (1997), "In defense of evidence-based teaching", British Educational Research Journal, Vol. 23 No. 4, pp. 405-419.

Hattie, J. (2013), Visible Learning: A Synthesis of over 800 Meta-Analyses Relating To Achievement, Routledge, London. 


\section{IJLLS \\ 9,3}

Haug, P. (2010), "Approaches to empirical research on inclusive education”, Scandinavian Journal of Disability Research, Vol. 12 No. 3, pp. 199-209.

Haug, P. (2017), "Understanding inclusive education: ideals and reality", Scandinavian Journal of Disability Research, Vol. 19 No. 3, pp. 206-217.

Higginson, R. and Chatfield, M. (2012), "Together we can do it: a professional development project for regular Teachers' of children with autism spectrum disorder", Kairaranga, Vol. 13 No. 2, pp. 29-40.

Hinton, S., Sofronoff, K. and Sheffield, J. (2008), "Training teachers to manage students with Asperger's syndrome in an inclusive classroom setting”, The Australian Educational and Development Psychologist, Vol. 25 No. 2, pp. 34-48.

Ho, F., Sze-Ching, L., Ka-Lam, S. and Arthur-Kelly, M. (2018), “An exploratory study on collaborative models for professional development and learning for teachers of students with autism spectrum disorder (ASD)", Collaborative Modes of Professional Development and Learning. NASEN, Vol. 33 No. 2, pp. 142- 164.

Holmqvist, M. (2017), "Models for collaborative professional development for teachers in Mathematics", International Journal for Lesson and Learning Studies, Vol. 6 No. 3, pp. 190-201.

Humphrey, N. and Lewis, S. (2008), "Make me normal' the views and experiences of pupils on the autistic spectrum in mainstream secondary schools", The International Journal of Research and Practice, Vol. 12 No. 1, pp. 23-46.

Humphrey, N. and Symes, W. (2010), "Perceptions of social support and experience of bullying among pupils with autistic spectrum disorders in mainstream secondary schools", European Journal of Special Needs Education, Vol. 25 No. 1, pp. 77-91.

James, W. and Thayer, H.S. (1975), Pragmatism, Harvard University Press, Vol. 1.

Jensen, L. (2017), Inkluderingskompetens vid adhd and autism, Be My Rails, Litauen.

Jones, M., Weber, K. and McLaughlin, T.F. (2013), "No teacher left behind: educating students with ASD and ADHD in the inclusion classroom", The Journal of Special Education Apprenticeship, Vol. 2 No. 2, pp. 2-22.

Klassen, R.M. and Chiu, M.M. (2010), "Effects on teachers' self-efficacy and job satisfaction: teacher gender, years of experience, and job stress", Journal of Educational Psychology, Vol. 102 No. 3, pp. 741-756.

Klassen, R.M., Tze, V.M., Betts, S.M. and Gordon, K.A. (2011), “Teacher efficacy research 1998- 2009; Signs of progress or unfulfilled promise?”, Educational Psychology Review, Vol. 23 No. 1, pp. 21- 43.

Kosko, K.W. and Wilkins, J.L.M. (2009), "General educators' in-service training and their self-percieved ability to adapt instruction for students with IEPs", Teacher Training and Inclusion, Vol. 33 No. 2, pp. 1-10.

Küller, R. (1991), "Environmental assessment from a neuropsychological perspective”, in Gärling, T. and Evans, G.W. (Eds), Environment, Cognition and Action: An Integrated Approach, Oxford University Press, New York, pp. 111-147.

Larcombe, T., Joosten, A., Cordier, R. and Vaz, S. (2019), "Preparing children with autism for transition to mainstream school and perspectives on supporting positive school experiences", Journal of Autism and Developmental Disorders, Vol. 49 No. 8, pp. 3073-3088.

Lewis, C., Perry, R. and Murata, A. (2006), "How should research contribute to instructional improvement? The case of Lesson Study", Educational Researcher, Vol. 35 No. 3, pp. 3-14.

Lewis, C., Perry, R., Fredkin, S. and Roth, J. (2012), "Improving teaching does improve teachers: evidence from lesson study", Journal of Teacher Education, Vol. 63 No. 5, pp. 368-375.

Lewis, C. (2015), "What is improvement science? Do we need it in education?", Educational Researcher, Vol. 44 No. 1, pp. 54-61. 
Linton, A.-C. (2015), "To include or not to include: teachers' social representations of inclusion of students with asperger syndrome”, Doctoral thesis, Linköping Studies in Arts and Science, Linköping, No. 656.

Lukito, S., Jones, R.G.C., Pickles, A., Baird, G., Happé, F., Charman, T. and Simonoff, E. (2017), "Specificity of executive function and theory of mind performance in relation to attentiondeficit/hyperactivity symptoms in autism spectrum disorders", Molecular Autism, Vol. 8 No. 60.

Marton , F. and Tsui, A.B. (2004), Classroom Discourse and the Space of Learning, Erlbaum, Mahwah, NJ.

Morrier, M.J., Hess, K.L. and Heflin, J.L. (2011), "Teacher training for implementation of teaching strategies for students with autism spectrum disorders", Teacher Education and Special Education, Vol. 34 No. 2, pp. 119-132.

Munthe, E., Bjuland, R. and Helgevold, N. (2016), "Lesson study in field practice: a time- lagged experiment in initial teacher education in Norway", International Journal for Lesson and Learning Studies, Vol. 5 No. 2, pp. 142-154.

Mutch-Jones, K., Puttick, G. and Minner, D. (2012), "Lesson study for accessible science: building expertise to improve practice in inclusive science classrooms", Journal of Research in Science Teaching, Vol. 49 No. 8, pp. 1012-1034.

Odom, S., Cox, A. and Brock, M. (2013), "Implementation science, professional development and autism spectrum disorders", Exceptional Children, Vol. 79 No. 2, pp. 233-251.

Parsons, S., Guldberg, K., MacLeod, A., Prunty, A. and Balfe, T. (2011), "Implications for practice from International review of the evidence on best practice in educational provision for children on the autism spectrum", European Journal of Special Needs Education, Vol. 26 No. 1, pp. 47-63.

Pring, R. (2000), Philosophy of Educational Researc, 3rd ed., Bloomsbury, London.

Ruble, L., Toland, M., Birdwhistell, J., McGrew, J. and Usher, E. (2013), "Preliminary study of the autism self-efficacy scale for teachers (ASSET)", Research in Autism Spectrum Disorders, Vol. 7 No. 9, pp. 1151- 1159.

Scheuermann, B., Webber, J., Boutot, E.A. and Goodwin, M. (2003), "Problems with personnel preparation in autism spectrum disorders", Focus on Autism and Other Developmental Disabilities, Vol. 18 No. 3, pp. 197-206.

Sharma, S. (1996), Applied Multivariate Techniques, John Wiley and Sons, New York.

Sousa, P., Dias, P.C. and Cadime, I. (2017), "Predictors of primary school teachers'knowledge about developmental dyscalculia", European Journal of Special Education, Vol. 32 No 2, pp. 204-220.

Spencer, S. (2011), "Universal design for learning: assistance for teachers in Today's inclusive classrooms", Interdisciplinary Journal of Teaching and Learning, Vol. 1 No. 1, pp. 10-22, SPSS, Software, version 25 .

Steinberg, J. (2018), “Ledarskap för klassrummet”, Handbok för arbetsro och effektivt lärande, Gothia, Stockholm.

Tamm, L., Duncan, A., Vaughn, A., McDale, R., Estell, N., Birnschein, A. and Crosby, L. (2019), "Academic needs in middle school: perspectives of parents and youth with autism", Journal of Autism and Developmental Disorders, pp. 1-14, doi: 10.1007/s10803-019-03995-1, (accessed 21 January 2020).

Timperley, H., Wilson, A. and Fung, I. (2007), Teacher Professional Learning and Development:Best Evidence Synthesis Iteration (BES), Ministry of Education, Wellington.

UNESCO (2005), Guidelines for Inclusion: Ensuring Access to Education for All, UNESCO, Paris.

Vetenskapsrådet (2002), Forskningsetiska Principer Inom Humanistisk-Samhällsvetenskaplig Forskning (Research Ethical Principles), Stockholm, available at: http://www.codex.vr.se/texts/HSFR.pdf (accessed 22 May 2019). 
IJLLS

9,3

Watkins, L.B., Ledbetter-Cho, K., O'reilly, M., Barnard-Brak, L. and Garcia-Grau, P. (2019), "Interventions for students with Autism in inclusive settings: a best-evidence synthesis and meta-analysis", Psychological Bulletin, Vol. 145 No. 5, pp. 490-507.

Wong, C., Odom, S., Hume, K., Cox, A., Fettig, A., Kucharczyk, S., Brock, M., Plavnick, J., Fleury, V. and Schultz, T. (2015), "Evidence-based practices for children, youth and young adults with autism spectrum disorder: a comprehensive review", Journal of Autism and Developmental Disorders, Vol. 45, pp. 1951-1966.

World Health Organisation (WHO) (2013), Autism Spectrum Disorders \& Other Developmental disorders. From Raising Awareness to Building Capacity, Geneva, available at: http://www.who. int/mental_health/maternal-child/autism_report/en.

\section{Further reading}

Dewey, J. (1999), Individualism Old and New, Prometheus Books, Amherst, NY.

Individuals With Disabilities Act (IDEA), Pub. L. No 101-476, 104 Stat. 110 (1990), available at: http:// nichcy.org/wp-content/uploads/docs/PL108-446.pdf.

No Child Left Behind Act of 2001, Pub. L. No. 107-110, 115 Stat. 1425 (2001), available at: http://www2. ed.gov/policy/elsec/leg/esea02/index.htmllo.

Norwich, B. and Jones, J. (2014), (Eds), Lesson Study-Making a Difference to Teaching Pupils with Learning Difficulties, Bloomsbury publishing Plc, London. 
Appendix 1

Teachers'

capacity to

\begin{tabular}{lccrrr}
\hline Outcome variable & Preintervention & Postintervention & Difference & $\begin{array}{r}\text { create learning } \\
\text { environments }\end{array}$ \\
\cline { 1 - 3 } Classroom organization & 9 & 10 & +1 & \\
Placement & 7 & 15 & +8 & $\mathbf{2 4 3}$ \\
Stimuli sanitizing & 15 & 20 & +2 & +3 & \\
Prepared facilities & 5 & 7 & +1 & Table A1. \\
Small group arrangement & 8 & 3 & +3 & Raw data, themes from \\
Multisensory tools & 2 & 3 & +1 & +24 & the physical area \\
Retreat room & - & 1 & &
\end{tabular}

\section{Appendix 2}

\begin{tabular}{|c|c|c|c|c|}
\hline Outcome variable & Preintervention & Postintervention & Difference & \\
\hline Individual schedule & 12 & 12 & _- & \\
\hline Placement & 7 & 8 & +1 & \\
\hline Clear instructions & 12 & 14 & +2 & \\
\hline Structure & 10 & 13 & +3 & \\
\hline $\begin{array}{l}\text { Compensatorical aids (computer, time help aids, } \\
\text { audiobooks) }\end{array}$ & 15 & 21 & +6 & \\
\hline Routines & 7 & 9 & +2 & \\
\hline Visual support & 15 & 18 & +3 & \\
\hline Break possibilities & 8 & 15 & +7 & \\
\hline Concrete material & 2 & 2 & - & \\
\hline Visual learning & 3 & 3 & - & \\
\hline Adjustments in tasks & 12 & 17 & +5 & \\
\hline Preparation/transitions & 5 & 13 & +8 & \\
\hline Repetition for working memory & 1 & 7 & +6 & \\
\hline Reward system & - & 4 & +4 & \\
\hline Classroom organization & 1 & 2 & +1 & Table A2. \\
\hline Positive reinforcement & - & 1 & +1 & Raw data, themes from \\
\hline Total & 110 & 159 & +49 & the pedagogical area \\
\hline
\end{tabular}




\section{IJLLS \\ Appendix 3 \\ 9,3}

\begin{tabular}{lcrr}
\hline Outcome variable & Preintervention & Postintervention & Difference \\
\hline Friendship support & 9 & 11 & +2 \\
Encouragement & 2 & 2 & - \\
Relation teacher-student & 3 & 12 & +9 \\
The whole class values & 5 & 6 & +1 \\
Transition support & 4 & 7 & +3 \\
Social stories & 7 & 7 & - \\
Recess activities & 6 & 8 & +2 \\
Support peer-groups & 4 & 12 & +8 \\
Social codes instruction & 1 & 3 & +2 \\
Positive reinforcement & 1 & 9 & +8 \\
Greetings - confirmation & - & 2 & +2 \\
Diverting maneuvering & - & 3 & +3 \\
The student's interest & - & 2 & +2 \\
Total & 42 & 84 & +42
\end{tabular}

Table A3.

Raw data, themes from The student's interest

the psychosocial area Total

\section{Corresponding author}

Emma Leifler can be contacted at: emma.leifler@gu.se

For instructions on how to order reprints of this article, please visit our website: 